\title{
O USO DA MÁSCARA LARÍNGEA PELO ENFERMEIRO NA RESSUSCITAÇÃO CARDIOPULMONAR: REVISÃO INTEGRATIVA DA LITERATURA
}

\author{
Cesar Eduardo Pedersoli ${ }^{1}$, Maria Célia Barcellos Dalri², Renata Cristina Pereira de Campos Silveira ${ }^{3}$, \\ Tânia Couto Machado Chianca ${ }^{4}$, Regilene Molina Zacaleri Cyrillo ${ }^{5}$, Cristina Maria Galvão ${ }^{6}$
}

\footnotetext{
${ }^{1}$ Doutorando em Enfermagem pela Escola de Enfermagem de Ribeirão Preto (EERP) da Universidade de São Paulo (USP). Enfermeiro do Serviço de Atendimento Móvel de Urgência (SAMU) da Secretaria Municipal da Saúde de Ribeirão Preto e da Unidade de Emergência do Hospital das Clínicas da Faculdade de Medicina de Ribeirão Preto da USP. São Paulo, Brasil. E-mail: cepedersoli@usp.br

${ }^{2}$ Doutor em Enfermagem. Professor Livre-Docente do Departamento de Enfermagem Geral e Especializada (DEGE) da EERP/ USP. São Paulo, Brasil. E-mail: macdalri@eerp.usp.br

${ }^{3}$ Doutor em Enfermagem. Professor do DEGE da EERP/USP. São Paulo, Brasil. E-mail: recris@eerp.usp.br

${ }^{4}$ Doutor em Enfermagem. Professor da Universidade Federal de Minas Gerais. Minas Gerais, Brasil. E-mail: tchianca@hotmail.com

${ }^{5}$ Doutor em Enfermagem. Docente do Curso de Enfermagem do Centro Universitário Barão de Mauá. Enfermeira do SAMU da Secretaria Municipal da Saúde de Ribeirão Preto. São Paulo, Brasil. E-mail: regizacareli@yahoo.com.br

${ }^{6}$ Doutor em Enfermagem. Professor Titular do DEGE da EERP/USP. São Paulo, Brasil. E-mail: crisgalv@eerp.usp.br
}

\begin{abstract}
RESUMO: O objetivo do estudo foi identificar as evidências disponíveis na literatura sobre a abordagem de vias aéreas por meio da inserção da máscara laríngea pelo enfermeiro, na ressuscitação cardiopulmonar, em pacientes adultos. O referencial teórico-metodológico utilizado foi a Prática Baseada em Evidências. Foi utilizada a revisão integrativa da literatura com o propósito de reunir e sintetizar o conhecimento existente sobre a temática proposta. As bases acessadas foram: LILACS, PUBMED, CINAHL e COCHRANE, com os descritores controlados "laryngeal masks", "cardiopulmonary resuscitation" e "nursing", sendo selecionados 18 estudos. Os resultados evidenciaram que a máscara laríngea é de fundamental importância para manejo de vias aéreas em situações críticas, necessita de treinamento para sua utilização e mostrou-se eficaz, atingindo taxas de sucesso próximas a 100\%. O grande impacto dos estudos publicados na década de 90 foi evidenciado nas diretrizes de ressuscitação cardiopulmonar publicadas em 2005, pois as embasaram, e foram citados nas mesmas.
\end{abstract}

DESCRITORES: Máscaras laríngeas. Ressuscitação cardiopulmonar. Enfermagem.

\section{NURSING USE OF LARYNGEAL MASKS IN CARDIOPULMONARY RESUSCITATION: AN INTEGRATIVE LITERATURE REVIEW}

\begin{abstract}
This study aimed to identify available evidence in literature about airway management by nurses through the insertion of the laryngeal mask during cardiopulmonary resuscitation in adult patients. In order to do so, the integrative literature review method was adopted, which aims to join and synthesize existing knowledge on the proposed theme. The following databases were accessed: LILACS, PUBMED, CINAHL and COCHRANE, using the controlled descriptors "laryngeal masks", "cardiopulmonary resuscitation", and "nursing". After exhaustive reading of the relevant articles, 18 references were selected. The results evidence that laryngeal masks are fundamentally important for airway management in critical situations and require training for their use. Laryngeal masks also proved themselves to be effective, reaching success levels of nearly 100\%. The strong impact of studies published in the 1990's was evidenced in the Brazilian 2005 cardiopulmonary resuscitation guidelines, serving as a basis and receiving citation as such.
\end{abstract}

DESCRIPTORS: Laryngeal masks. Cardiopulmonary resuscitation. Nursing.

\section{EL USO DE LA MASCARILLA LARÍNGEA POR EL ENFERMERO EN LA REANIMACIÓN CARDIOPULMONAR: REVISIÓN INTEGRADORA DE LA LITERATURA}

\begin{abstract}
RESUMEN: El estudio tuvo como objetivo identificar las evidencias disponibles en la literatura sobre el manejo de las vías aéreas por el enfermero, mediante la inserción de la mascarilla laríngea en la reanimación cardiopulmonar en pacientes adultos. La metodología adoptada fue la revisión integradora de la literatura con el fin de reunir y sintetizar los conocimiento sobre el tema propuesto. Las bases de datos consultadas son: LILACS, PUBMED, CINAHL y COCHRANE, con los descriptores controlados: "laryngeal masks", "cardiopulmonary resuscitation" y "nursing". Después de una lectura exhaustiva de los artículos se seleccionaron 18 estudios. Los resultados mostraron que la mascarilla laríngea es de fundamental importancia para el manejo de las vías aéreas en situaciones críticas, se necesita de entrenamiento para su utilización y se mostró eficaz, con tasas de éxito de casi $100 \%$. Se verificó que el gran impacto de los estudios publicados en la década del noventa se hizo evidente en las directrices de 2005 sobre reanimación cardiopulmonar, ya que se basaron y citaron en las mismas.
\end{abstract}

DESCRIPTORES: Mascarilla laríngea. Reanimación cardiopulmonar. Enfermería. 


\section{INTRODUÇÃO}

A Parada Cardiorrespiratória (PCR) é uma situação que requer uma atuação imediata dos profissionais da saúde, demanda ações básicas e avançadas de suporte de vida, com diferentes componentes de recursos e dispositivos necessários à execução dos procedimentos. Na maioria dos hospitais, unidades básicas e distritais de saúde, entre outras instituições da área, os profissionais da equipe de enfermagem (enfermeiros, auxiliares e/ou técnicos), em várias situações, são os primeiros a chegar à cena dos casos de PCR, devendo ser competentes para iniciar as manobras de Ressuscitação Cardiopulmonar (RCP). ${ }^{1}$

O enfermeiro detém o potencial de ser importante elemento da equipe de saúde, já que possui competência técnica, institucional e legal para iniciar os procedimentos de RCP, de forma que deverá estar familiarizado e capacitado para executar tais manobras, atendendo às diretrizes estabelecidas pela American Heart Association (AHA). ${ }^{2}$

Cabe à equipe de enfermagem a responsabilidade pelos cuidados intensivos ao paciente em PCR, durante a RCP e após essa intervenção, por meio da avaliação permanente, da vigilância e da realização de procedimentos e técnicas que complementam a terapêutica médica, embasado em diretrizes para a assistência de enfermagem, garantindo a continuidade de um trabalho integrado. ${ }^{3}$

A falha no manejo de vias aéreas ainda é considerada um dos maiores fatores que resultam em piores resultados em situação de anestesia, emergências médicas e terapia intensiva. Garantir uma via aérea pérvea é prioridade absoluta, implicando na realização simultânea de ações de desobstrução e manutenção. Em condições em que a ventilação está difícil e a oxigenação prejudicada (como por exemplo, na PCR), manobras avançadas ou métodos alternativos podem ser necessários. ${ }^{4}$

Um dos dispositivos atualmente recomendados para utilização pelos profissionais durante a RCP é a máscara laríngea, a qual consiste em um tubo semelhante ao endotraqueal, com uma máscara inflável na extremidade distal apropriada para adaptação à faringe posterior, selando a região da base da língua e da abertura laríngea. Mais recentemente, tem recebido atenção especial como ferramenta para o manejo de vias aéreas difíceis. ${ }^{5}$

A abordagem das vias aéreas é um desafio durante a RCP e, frequentemente, o enfermeiro é o primeiro a deparar-se com o paciente em PCR. A máscara laríngea, quando utilizada de maneira adequada, tende a minimizar complicações, como por exemplo, a regurgitação, tendo como desfecho o estabelecimento de uma via aérea segura, possibilitando maiores chances de sucesso na ressuscitação.

O objetivo do presente estudo foi identificar as evidências disponíveis na literatura sobre a abordagem de vias aéreas por meio da inserção da máscara laríngea pelo enfermeiro, na ressuscitação cardiopulmonar em pacientes adultos.

O referencial metodológico adotado foi o da Prática Baseada em Evidências (PBE), uma abordagem que incorpora resultados de pesquisas, a competência clínica do profissional e as preferências do cliente para a tomada de decisão sobre a assistência à saúde. $^{6}$

Para avaliar a qualidade de tais pesquisas, $\mathrm{o}$ profissional de saúde deve compreender a abordagem metodológica na qual estão inseridas, sendo um aspecto de suma importância na PBE a busca da melhor evidência disponível. Esta deriva de pelo menos uma revisão sistemática de múltiplos e bem delineados estudos randomizados controlados. ${ }^{6}$

O quadro 1 a seguir apresenta e classifica a qualidade das evidências em sete níveis.

\section{Quadro 1 - Classificação dos níveis de evidências ${ }^{7}$}

\begin{tabular}{|c|l|}
\hline Nível & \multicolumn{1}{|c|}{ Força de evidência } \\
\hline I & $\begin{array}{l}\text { Evidência proveniente de uma revisão sistemática ou metanálise de todos os ensaios clínicos randomizados } \\
\text { controlados ou oriundas de diretrizes baseadas em revisões sistemáticas de ensaios clínicos randomizados } \\
\text { controlados }\end{array}$ \\
\hline II & Evidência obtida de pelo menos um ensaio clinico randomizado controlado bem delineado \\
\hline III & Evidência proveniente de um bem desenhado estudo controlado sem randomização \\
\hline IV & Evidência proveniente de um bem desenhado estudo caso-controle ou coorte \\
\hline V & Evidência proveniente de uma revisão sistemática de estudos qualitativos e descritivos \\
\hline VI & Evidência de um único estudo descritivo ou qualitativo \\
\hline VII & Evidência proveniente da opinião de autoridades e/ou relatórios de comitês de especialistas \\
\hline
\end{tabular}


A síntese dos resultados de pesquisas relevantes e reconhecidos mundialmente facilita a incorporação de evidências, ou seja, facilita a transferência de conhecimento novo para a prática. $^{8}$

Este estudo teve como foco mostrar que o enfermeiro pode ser capaz de utilizar a máscara laríngea na RCP de maneira eficaz, tomar decisões, realizar intervenções de maneira imediata e com autonomia, com o intuito final de prestar assistência de qualidade ao paciente.

\section{OBJETIVO}

Identificar as evidências disponíveis na literatura sobre a abordagem de vias aéreas, por meio da inserção da máscara laríngea pelo enfermeiro, na ressuscitação cardiopulmonar, em pacientes adultos.

\section{METODOLOGIA}

Para alcançar o objetivo desse estudo foi realizada uma revisão integrativa da literatura, com o propósito de reunir e sintetizar o conhecimento pré-existente sobre a temática proposta. Esta, sumariza as pesquisas realizadas sobre determinado assunto, construindo uma conclusão a partir de muitos estudos realizados separadamente, mas que investigam problemas idênticos ou similares. Os mesmos são analisados de forma sistemática em relação aos seus objetivos, materiais e métodos, permitindo dessa forma que o leitor analise o conhecimento sobre o tema abordado. ${ }^{9}$

As seguintes fases foram percorridas: identificação do tema, amostragem ou busca na literatura, categorização, avaliação dos estudos, interpretação dos resultados e a síntese do conhecimento evidenciado ou apresentação da revisão integrativa. A pergunta norteadora do processo revisional foi construída através da estratégia PICO (P=Paciente ou Problema, I=Intervenção, $\mathrm{C}=$ Comparação ou controle, $\mathrm{O}=$ Outcomes ou desfechos $)^{10}$ e consistiu em: quais são as evidências científicas disponíveis na literatura relacionadas à utilização da máscara laríngea pelo enfermeiro, na ressuscitação cardiopulmonar em pacientes adultos?

A seleção dos artigos se deu a partir das bases de dados eletrônicas LILACS (Literatura LatinoAmericana e do Caribe em Ciências da Saúde), PUBMED, CINAHL (Cumulative Index to Nursing and Allied Health Literature) e Biblioteca Cochrane.
Os descritores utilizados neste estudo foram os controlados, ou seja, aqueles estruturados e organizados para facilitar o acesso à informação ${ }^{11}$ : cardiopulmonary resuscitation (ressuscitação cardiopulmonar), laryngeal masks (máscaras laríngeas) e nursing (enfermagem). Esses vocabulários são usados como um filtro entre a linguagem apropriada do autor e aquela da terminologia da área, reconhecida mundialmente. ${ }^{12}$

Os critérios de inclusão dos estudos selecionados foram: aqueles publicados em inglês, espanhol e português; que retratavam procedimentos, intervenções ou diretrizes sobre ressuscitação cardiopulmonar, máscara laríngea e enfermagem; e período de 1960 a 2008. Os critérios de exclusão adotados foram: impossibilidade de aquisição do artigo na íntegra e/ ou aqueles que abordassem intervenções em pacientes pediátricos, devido à predominância epidemiologicamente mais significante da parada cardiorrespiratória nos adultos.

Foram obtidos na base de dados Pubmed 18 artigos, na CINAHL, seis, na base de dados COCHRANE, cinco, e na LILACS, dois, totalizando 31 estudos. Numa avaliação inicial verificou-se que os dois estudos encontrados na base de dados LILACS apresentavam impossibilidade de aquisição na íntegra, portanto, foram excluídos da revisão. Tal impossibilidade se deu pelo fato dos artigos não estarem disponíveis por meio eletrônico ou para aquisição através do Sistema de Comutação Bibliográfica (COMUT). Em relação à base de dados Cochrane, constatou-se que três eram duplicados, pois já haviam sido também selecionados na base de dados Pubmed. Portanto, foi obtida uma amostra inicial de 26 estudos para análise. Após leitura exaustiva dos mesmos constatou-se a necessidade de serem excluídos outros oito, por não atenderem aos critérios de inclusão previamente definidos.

Em relação à busca, utilizando os descritores controlados, na base de dados Pubmed encontrou-se 18 referências, sendo excluídas quatro; na consulta à CINAHL, obteve-se seis estudos, dos quais três foram excluídos; na LILACS, localizouse duas referências que foram excluídas. Tais exclusões se deram pelo fato de os artigos não atenderem aos critérios do dispositivo selecionado. Finalmente, a busca na Biblioteca Cochrane resultou em cinco estudos, dos quais excluiu-se quatro (três duplicados na Pubmed e um após leitura aprofundada). Assim, foram selecionados e analisados 18 artigos. 
Para a extração de dados dos artigos foi utilizado um instrumento, previamente validado com autorização do autor ${ }^{13}$, o qual contempla os itens: identificação do artigo original, características metodológicas do estudo, avaliação do rigor metodológico, intervenções estudadas e resultados encontrados.

A análise dos dados extraídos foi realizada de forma descritiva, a qual permitiu avaliar as evidências ${ }^{7}$, identificar a necessidade de investigações futuras acerca da temática e oferecer fundamentos para a prática profissional.

\section{RESULTADOS E DISCUSSÃO}

A presente revisão integrativa da literatura objetivou buscar as evidências científicas disponíveis acerca do uso da máscara laríngea na RCP, pelo enfermeiro. A meta foi sintetizar o conhecimento nessa temática, contextualizando o seu momento histórico em relação às diretrizes da RCP, de 2000 e 2005, para fundamentar a prática clínica do enfermeiro, pois a RCP demanda tomada de decisão imediata, conhecimento técnico cientifico e habilidades psicomotoras.

Quadro 2 - Distribuição dos artigos segundo título, ano de publicação, periódico e nível de evidência

(Continua)

\begin{tabular}{|c|c|c|c|c|c|c|}
\hline & TÍTULO & ANO & AUTORES & PERIÓDICO & $\begin{array}{l}\text { BASE DE } \\
\text { DADOS }\end{array}$ & EVID \\
\hline 1 & $\begin{array}{l}\text { The laryngeal mask in cardiopulmonary } \\
\text { resuscitation in a district general hospital: a } \\
\text { preliminary communication }\end{array}$ & 1993 & $\begin{array}{l}\text { Leach A Alexander } \\
\text { CA Stone B }\end{array}$ & Resuscitation & Pubmed & VI \\
\hline 2 & $\begin{array}{l}\text { A comparison of the laryngeal mask airway } \\
\text { and Guedel airway, bag and facemask for } \\
\text { manual ventilation following formal training }\end{array}$ & 1993 & $\begin{array}{c}\text { Alexander R Hodgson } \\
\text { P Lomax D } \\
\text { Bullen C } \\
\end{array}$ & Anaesthesia & COCHRANE & III \\
\hline 3 & $\begin{array}{l}\text { Immediate management of the airway during } \\
\text { cardiopulmonary resuscitation in a hospital } \\
\text { without a resident anaesthesiologist }\end{array}$ & 1994 & $\begin{array}{c}\text { Verghese C } \\
\text { Prior-Willeard PFS } \\
\text { Baskett, PFJ } \\
\end{array}$ & $\begin{array}{c}\text { European Jour- } \\
\text { nal of Emergen- } \\
\text { cy Medicine }\end{array}$ & Pubmed & IV \\
\hline 4 & $\begin{array}{l}\text { The use of the laryngeal mask airway by } \\
\text { nurses during cardiopulmonary resuscitation }\end{array}$ & 1994 & Martens P & Anaesthesia & Pubmed & VII \\
\hline 5 & $\begin{array}{l}\text { The use of the laryngeal mask airway by } \\
\text { nurses during cardiopulmonary resuscita- } \\
\text { tion. Results of a multicentre trial }\end{array}$ & 1994 & $\begin{array}{l}\text { Stone BJ } \\
\text { Leach AB Alexander } \\
\text { CA Ruffer DR } \\
\text { Baskett PJF et.al. }\end{array}$ & Anaesthesia & Pubmed & VI \\
\hline 6 & $\begin{array}{l}\text { The laryngeal mask: an essential part of } \\
\text { emergency airway management }\end{array}$ & 1996 & Eastwick-Field P & $\begin{array}{l}\text { Accident and } \\
\text { Emergency } \\
\text { Nursing }\end{array}$ & Pubmed & VII \\
\hline 7 & $\begin{array}{l}\text { Airway management training using the } \\
\text { laryngeal mask airway: a comparison of two } \\
\text { different training programmes }\end{array}$ & 1997 & $\begin{array}{c}\text { Roberts I } \\
\text { Allsop P Dickinson M } \\
\text { Curry P } \\
\text { Eastwick-Field P } \\
\text { Eyre G } \\
\end{array}$ & Resuscitation & $\begin{array}{l}\text { Pubmed } \\
\text { COCHRANE }\end{array}$ & III \\
\hline 8 & $\begin{array}{l}\text { Tracheal intubation via the laryngeal mask } \\
\text { airway: a viable alternative to direct laryn- } \\
\text { goscopy for nursing staff during cardiopul- } \\
\text { monary resuscitation }\end{array}$ & 1998 & $\begin{array}{l}\text { Bryden DC Gwinnutt } \\
\text { CL }\end{array}$ & Resuscitation & $\begin{array}{l}\text { Pubmed } \\
\text { COCHRANE }\end{array}$ & III \\
\hline 9 & $\begin{array}{l}\text { Airway management during cardiopulmo- } \\
\text { nary resuscitation-a comparative study of } \\
\text { bag-valve-mask, laryngeal mask airway and } \\
\text { combitube in a bench model }\end{array}$ & 1999 & $\begin{array}{c}\text { Dorges V } \\
\text { Sauer C } \\
\text { Ocker H } \\
\text { Wenzel V } \\
\text { Schmucker P } \\
\end{array}$ & Resuscitation & Pubmed & III \\
\hline 10 & $\begin{array}{l}\text { Emergency airway management by inten- } \\
\text { sive care unit nurses with the intubating la- } \\
\text { ryngeal mask airway and the laryngeal tube }\end{array}$ & 2000 & $\begin{array}{c}\text { Dorges V } \\
\text { Wenzel V Neubert E } \\
\text { Schmucker } \mathrm{P} \\
\end{array}$ & Critical Care & Pubmed & III \\
\hline 11 & Airway management-when and how? & 2001 & Lim BL & $\begin{array}{c}\text { Singapore Medi- } \\
\text { cal Journal }\end{array}$ & Pubmed & VII \\
\hline 12 & $\begin{array}{l}\text { Cardiopulmonary resuscitation: the laryngeal } \\
\text { mask airway }\end{array}$ & 2002 & Hand $\mathrm{H}$ & $\begin{array}{l}\text { Emergency } \\
\text { Nurse }\end{array}$ & Pubmed & VII \\
\hline
\end{tabular}




\begin{tabular}{|c|l|c|c|c|c|c|}
\hline & \multicolumn{1}{|c|}{ TíTULO } & ANO & AUTORES & PERIÓDICO & $\begin{array}{c}\text { BASE DE } \\
\text { DADOS }\end{array}$ & EVID \\
\hline 13 & Recent advances in emergency life support & 2002 & $\begin{array}{c}\text { Dries DJ } \\
\text { Sample MA }\end{array}$ & $\begin{array}{l}\text { Nursing Clinical } \\
\text { North American }\end{array}$ & Pubmed & VII \\
\hline 14 & $\begin{array}{l}\text { Use of laryngeal mask airway in pre-hospital } \\
\text { environments }\end{array}$ & 2002 & Castle N & $\begin{array}{c}\text { Emergency } \\
\text { Nurse }\end{array}$ & CINAHL & VII \\
\hline 15 & $\begin{array}{l}\text { Does attendance at an immediate life sup- } \\
\text { port course influence nurses' skill deploy- } \\
\text { ment during cardiac arrest? }\end{array}$ & 2004 & $\begin{array}{c}\text { Murphy M Fitzsimons } \\
\text { D }\end{array}$ & Resuscitation & Pubmed & VI \\
\hline 16 & $\begin{array}{l}\text { Insertion of the LMA-Unique with and with- } \\
\text { out digital intraoral manipulation by inexperi- } \\
\text { enced personnel after manikin-only training }\end{array}$ & 2004 & $\begin{array}{c}\text { Brimacombe J Keller } \\
\text { C }\end{array}$ & $\begin{array}{l}\text { Journal of Emer- } \\
\text { gency Medicine }\end{array}$ & Pubmed & COCHRANE \\
\hline 17 & $\begin{array}{l}\text { Reflection on a patient's airway manage- } \\
\text { ment during a ward-based resuscitation }\end{array}$ & 2006 & Shepherd C & $\begin{array}{c}\text { Nursing in Criti- } \\
\text { cal Care }\end{array}$ & CINAHL & VII \\
\hline 18 & $\begin{array}{l}\text { Maternal resuscitation: how to resuscitate } \\
\text { mothers who die? }\end{array}$ & 2008 & Madams M & $\begin{array}{l}\text { British Journal of } \\
\text { Midwifery }\end{array}$ & CINAHL & VII \\
\hline
\end{tabular}

Observou-se que, em relação ao ano de publicação, totalizaram nove (50\%) na década de 90 ou seja, antecederam as diretrizes de RCP, do ano 2000. Após esse período, foram identificados até novembro de 2005, quando foram apresentadas as novas diretrizes para Ressuscitação Cardiopulmonar, sete artigos (39\%). Posteriormente, foram publicados dois (11\%), até o ano de 2008.

Em relação aos periódicos, cinco estudos estavam publicados (28\%) na Resuscitation, três (17\%) na Anaesthesia, dois (11\%) na Emergency Nurse e um artigo $(5,5 \%)$ em cada um dos periódicos a seguir: Journal of Emergency Medicine, Nursing Clinical North American, Singapore Medical Journal, Critical Care, Accident and Emergency Nursing, European Journal of Emergency Medicine, British Journal of Midwifery e Nursing in Critical Care.

Ao serem analisados os delineamentos de pesquisa foram encontrados seis $(33,3 \%)$ de delineamento quase-experimental. Os artigos de delineamento não experimental somaram 12 (66,6\%), sendo três do tipo survey/descritivo/exploratório $(25 \%)$, um prospectivo $(8,5 \%)$ e oito relatos de experiência/opinião de especialista $(66,5 \%)$.

No que tange à força de evidência, seis possuem nível de evidência III (33,5\%), um possui nível de evidência IV (5,5\%), três possuem nível de evidência VI $(17 \%)$ e oito foram classificados com o nível de evidência VII (44\%).

Após leitura e análise dos estudos selecionados, optou-se por agrupá-los em três momentos históricos, a saber: a) aqueles que precederam as diretrizes de ressuscitação cardiopulmonar do ano de 2000; b) os publicados no período entre as diretrizes de 2000 e as diretrizes de 2005; e c) após as diretrizes de ressuscitação cardiopulmonar do ano de 2005.
Verificou-se que 10 estudos foram publicados entre 1993 e 2000, ou seja, no período que antecede a publicação das diretrizes de ressuscitação cardiopulmonar ao final do ano 2000, mas não incidiram em grande impacto nas mesmas. Observou-se que a ênfase dada na diretriz acerca da abordagem das vias aéreas ficou centrada, predominantemente, na intubação endotraqueal a qual, como já descrita anteriormente, deve ser realizada por profissionais devidamente treinados e com frequente execução do procedimento, que não se caracteriza como uma prática do enfermeiro. Abordam desde opiniões de especialistas acerca da importância da máscara laríngea durante a ressuscitação até a comparação da mesma com outros dispositivos já consagrados, como por exemplo, a unidade bolsa-valva-máscara, sendo que a amostra era composta por enfermeiros.

Os resultados apresentados nos estudos 2, 7, 8, 9 e 10 apontaram o uso da máscara laríngea como um dispositivo de primeira escolha, pelo enfermeiro, no controle de vias aéreas. Nesse sentido, utilizaram como estratégia o treinamento de enfermeiros em laboratório e em manequins adaptados para simular parâmetros de avaliação de desempenho dos sujeitos. Também foi avaliado o desfecho da eficácia da máscara laríngea em comparação com a de Guedel, o ambú e o combitubo. O uso do manequim para treinamento de inserção da máscara laríngea mostrou-se eficaz, mas reitera a necessidade de pesquisas que façam um seguimento desses profissionais, no decorrer do tempo, com o intuito de avaliar se há perda das habilidades para manuseio e utilização dessa ferramenta.

Com base nessa revisão, o resultado dos demais estudos $(1,3,4,5,6)$ apresentados nesse gru- 
po, também contemplam, nas suas investigações, o treinamento de enfermeiros para o uso da máscara laríngea em situação de PCR. É oportuno ressaltar que o uso da máscara laríngea em situação de PCR é encorajado nos resultados das investigações com reforço para ser usado em larga escala pelo enfermeiro. O uso da máscara laríngea, por enfermeiros, após treinamento, evidenciou seu envolvimento durante a ressuscitação e, sobretudo, mostrou que a precocidade do atendimento resultou em aumento das taxas de sobrevivência e alta hospitalar.

O uso da máscara laríngea pode ser confiável, realizado por enfermeiros e, num curto espaço de tempo, a técnica promove isolamento da via aérea durante a ressuscitação. $\mathrm{O}$ manejo da via aérea, adquirido durante a $\mathrm{RCP}$, associado à baixa incidência de complicações encoraja a ampliação do uso da máscara laríngea, por enfermeiros, durante a ressuscitação cardiopulmonar.

Diante do exposto, a máscara laríngea é um dispositivo confiável por permitir ao enfermeiro, em situação de emergência, e no atendimento precoce da PCR, garantir uma via aérea pérvea, segura, além de baixa incidência de complicações (distensão gástrica e regurgitação), promoção de adequada ventilação e consequente aumento da sobrevida.

Nos estudos publicados que precederam as diretrizes da RCP, do ano de 2000, consagrou-se uma oportunidade para a prática clínica do enfermeiro, em relação ao evento da PCR, com apropriação de equipamento voltado para intervenções de enfermagem diretas no controle de vias aéreas, através do uso da máscara laríngea, visando o aumento da sobrevida dos pacientes.

Os estudos publicados entre as diretrizes de 2000 e as de 2005 são, em sua maioria, de caráter descritivo, e nenhum deles é citado na publicação dos Guidelines 2005, mostrando que o embasamento cientifico para recomendar o uso da máscara laríngea na ressuscitação foi obtido a partir de trabalhos realizados na década de 90 .

As diretrizes de Ressuscitação Cardiopulmonar publicadas em 2000, pela AHA e pela European Resuscitation Council (ERC), descrevem o tubo endotraqueal como a medida coadjuvante de escolha para ventilação. Publicação acerca de tais diretrizes ${ }^{14}$ descreve a recomendação do uso da máscara laríngea, ainda de maneira incipiente, mas como Classe IIa, na qual o peso da evidência suporta a ação ou terapia, sendo esta considerada aceitável e útil. Busca-se cada vez mais alcançar as recomendações de classe I, as quais são baseadas em estudos prospectivos de alto nível, sustentando a ação ou terapia. A importância da máscara laríngea se dá em virtude de haver com frequência situações em que a intubação orotraqueal é um procedimento mal sucedido e o inadequado posicionamento do tubo não é detectado. ${ }^{14}$

Todas as recomendações para RCP devem ser idealmente baseadas em grandes ensaios clínicos controlados, randomizados e prospectivos, que detectem efeitos substanciais do tratamento na sobrevivência em longo prazo, e que sejam classificados como Classe I ou Classe IIa; classes essas que são caracterizadas por benefícios maiores que os riscos, sendo, no caso da Classe IIa, razoável, realizar o procedimento ou administrar o tratamento. Para as recomendações da Classe IIa, o peso das evidências dá respaldo à ação ou à terapia, sendo esta considerada aceitável e útil. ${ }^{14-15}$

Os artigos 11, 12, 13, 14 descrevem opiniões de especialistas, reiterando que a máscara laríngea trata-se de um dispositivo considerado como alternativa útil em relação à intubação endotraqueal, mostrando ser uma excelente oportunidade para a expansão da prática do enfermeiro e apontando avanços em suporte de vida nas emergências. Destacam que é uma ferramenta de fácil manuseio e inserção, que minimiza o risco de distensão gástrica e a consequente regurgitação e aspiração em relação à unidade bolsa-valva-máscara.

O estudo 15 explorou a relação entre o treinamento de um curso intitulado Immediate Life Support (ILS) e o uso por enfermeiros dessas habilidades em uma situação de PCR. Os autores concluíram que o curso ILS não resultou em aumento da utilização de habilidades por enfermeiros, pois relatam ausência de oportunidades para execução do conhecimento adquirido. Caracterizou-se por uma abordagem não experimental, estudo do tipo survey/descritivo/exploratório, nível de evidência VI.

O único estudo, de $\mathrm{n}^{\mathrm{o}} 16$ e de delineamento quase-experimental (nível de evidência III), avaliou o processo de inserção de máscara laríngea, por enfermeiros, utilizando técnica com e sem manipulação intra-oral.

Após a divulgação das diretrizes de ressuscitação em 2005, foram publicados apenas dois estudos, os quais são descritivos, ou seja, não houve publicações com maior nível de evidência, que apontassem a utilização do dispositivo máscara laríngea na ressuscitação, como recomendado por tais diretrizes (Classe IIa), e o impacto de tal intervenção, na prática de enfermagem. 
Verificou-se que o grande impacto dos estudos publicados na década de 90 foi evidenciado nas diretrizes publicadas em 2005, pois as embasaram e foram citados nas mesmas. Na publicação dos Guidelines da American Heart Association de 2005, são citados os estudos 1, 2, 3, 5, 7 e 9.

Os resultados obtidos na presente revisão integrativa da literatura evidenciam que as diretrizes de RCP, desde o ano 2000, já têm recomendado a utilização da máscara laríngea durante situações de emergência, sobretudo na PCR, como foi demonstrado pelo estudo 13 .

\section{CONCLUSÕES}

O tubo traqueal já foi o único método considerado ótimo para manejo da via aérea na PCR. Há consideráveis evidências que sem adequado treinamento ou manutenção frequente das habilidades, a incidência de falha na intubação e complicações (intubação esofageana ou deslocamento do tubo não reconhecidos) é inaceitavelmente alta. Tentativas prolongadas de intubação traqueal podem ser perigosas devido à cessação das compressões torácicas durante esse período, podendo comprometer a perfusão coronariana e cerebral. Profissionais de saúde treinados no uso de dispositivos supra-glóticos (como por exemplo, a máscara laríngea) devem considerar o seu uso para manejo da via aérea durante a PCR, bem como alternativa de resgate em vias aéreas difíceis ou quando ocorrer falha na intubação traqueal. ${ }^{16}$

Os estudos demonstraram que a máscara laríngea é de fundamental importância para omanejo de vias aéreas, em situações críticas, mas que os profissionais de saúde necessitam de treinamento para sua utilização e, quando testada em manequins, mostrou-se eficaz, atingindo taxas de sucesso em sua inserção e nas ventilações próximas a 100\%.

Devido à ausência de estudos com delineamento experimental, acerca da temática, evidencia-se a necessidade de investigações científicas envolvendo a máscara laríngea, a ressuscitação cardiopulmonar e a enfermagem, com o intuito de subsidiar a prática clínica do enfermeiro, e sua tomada de decisão acerca do cuidado a ser prestado ao paciente em situação de emergência, sobretudo na PCR.

Alguns aspectos merecem atenção, considerando a pouca participação dos enfermeiros como autores e pesquisadores, mas sujeitos dos estudos. Entretanto, é preciso considerar que sendo sujeitos das investigações, foi possível identificar, compre- ender e sinalizar aspectos relevantes dos atributos cognitivo, técnicos e demais habilidades para os enfermeiros executarem tal intervenção.

Entende-se que é necessário reunir esforços de grupos de interesses na investigação e com fomento de órgãos financiadores para ampliar estudos e pesquisas de intervenção, envolvendo o profissional enfermeiro. Esse pode ter importante papel na expansão dessa área de conhecimento, por meio de estudos de intervenção, tais como Ensaios Clínicos Randomizados Controlados (ECRC), abordando vias aéreas difíceis, por meio da utilização de dispositivos seguros.

A PBE é uma abordagem metodológica fundamental e relevante na busca de subsídios para a prática clínica do enfermeiro, diante dos avanços tecnológicos e da alta complexidade no cuidado de enfermagem em emergência, sendo essencial ferramenta na condução de tais investigações cientificas.

Cabe ressaltar que as diretrizes de ressuscitação cardiopulmonar publicadas em 2010, pela American Heart Association corroboram com o exposto, pois caracterizam a máscara laríngea como via aérea avançada na RCP, reconhecendo-a como um instrumento de grande valia, a ser utilizado na intervenção controle da via aérea. Com isso, propomos a incorporação de tal prática pelo enfermeiro, devidamente capacitado, conforme apontam os estudos analisados, podendo, assim, avaliar e intervir no controle da via aérea em risco.

\section{REFERÊNCIAS}

1. Pedersoli CE. O uso da máscara laríngea pelo enfermeiro na ressuscitação cardiopulmonar: revisão integrativa da literatura [dissertação]. Ribeirão Preto (SP): Escola de Enfermagem de Ribeirão Preto da Universidade de São Paulo. Programa de PósGraduação em Enfermagem Fundamental; 2009.

2. Granitoff N. Desfibrilação precoce praticada por enfermeiros: análise de fatores influenciadores [tese]. São Paulo (SP): Universidade Federal de São Paulo; 2003.

3. Dalri MCB, Araújo IEM, Silveira RCPC, CaniniSRMS, Cyrillo RMZ. Novas diretrizes da ressuscitação cardiopulmonar. Rev Latino-am Enfermagem. 2008 Nov-Dez; 16(6):1060-2.

4. Agro FE, Cataldo R, Mattei A. New devices and techniques for airway management. Minerva Anestesiol. 2008; 74:1-9.

5. Brocato C, Kett DH. Máscara laríngea no manuseio das vias aéreas. Rev Soc Cardiol Estado São Paulo. 1998 Jul-Ago; 8(4):650-4. 
6. Galvão CM, Sawada NO, Rossi LA. A prática baseada em evidências: considerações teóricas para sua implementação na enfermagem perioperatória. Rev Latino-am Enfermagem. 2002 Set-Out; 10(5):690-5.

7. Melnyk BM, Fineout-Overholt E. Making the case for evidence-based practice. In: Melnyk BM, FineoutOverholt E. Evidence-based practice in nursing \& healthcare. A guide to best practice. Philadelphia (US): Lippincot Willians \& Wilkins; 2005. p. 3-24.

8. Mendes KDS, Silveira RCCP, Galvão CM. Revisão integrativa: método de pesquisa para a incorporação de evidências na saúde e na enfermagem. Texto Contexto Enferm. 2008 Out-Dez; 17(4):58-64.

9. Polit DF, Beck CT, Hungler BP. Fundamentos de pesquisa em enfermagem. Métodos, avaliação e utilização. Trad. de Ana Thorell, $5^{a}$ ed. Porto Alegre (RS): Artmed; 2004.

10. Santos CMC, Pimenta CAM, Nobre MRC. A estratégia PICO para a construção da pergunta de pesquisa e busca de evidências. Rev Latino-am Enfermagem. 2007 Mai-Jun; 15(3):508-11.

11. Silveira RCCP. Filme transparente de poliuretano: evidências para a sua utilização no curativo de cateter venoso central de longa permanência [tese]. Ribeirão Preto (SP): Escola de Enfermagem de Ribeirão Preto da Universidade de São Paulo. Programa de Pós-Graduação em Enfermagem Fundamental; 2008.

12. Pellizzon RF. Pesquisa na área da saúde: 1. Base de dados DECs (Descritores em Ciências da Saúde). Acta Cir Bras. 2004; 19(2):153-63.

13. Ursi ES. Prevenção de lesões de pele no perioperatório: revisão integrativa da literatura [dissertação]. Ribeirão Preto (SP): Escola de Enfermagem de Ribeirão Preto da Universidade de São Paulo; 2005.

14. Latorre F, Nolan J, Robertson C, Chamberlain D, Baskett $P$. European resuscitation council guidelines 2000 for adult advanced life support. Resuscitation. 2001 Mar; 48(3):211-21.

15. American Heart Association. Guidelines for cardiopulmonary resuscitation and emergency cardiovascular care. International Consensus on Science. Circulation. 2005; 112: IV-1-IV-5.

16. Hazinski MF, Nolan JP, Billi JE, Böttiger BW, Bossaert L. 2010 International consensus on cardiopulmonary resuscitation and emergency cardiovascular care science with treatment recommendations. Circulation. 2010; 122(suppl 2):S250-75. 